\title{
The Evolution of a Tri-Layer Comforter by Using an Acrylic Felt Nonwoven Fabric
}

\author{
Mangalam R. Srikrishnan*, \\ Naganathan Archana and Joy Niresh \\ PSG College of Technology \\ Coimbatore, India
}

Received 24.03.2020, received in revised form 19.04.2020, accepted 21.05.2020

Abstract. This study is aimed at developing a home textile product, namely, comforter by using felt. Commercial triple layer comforter products consist of two outer fabric layers with a layer of insulation between them, i.e. middle layer is batting which is usually made of down feathers, polyester or wool. The four common major combinations taken for this study include, CF1C, CF2C, BF1B, BF2B (C Cotton, B - Bamboo, F1 - 270 gsm Acrylic felt, F2 - 370 gsm Acrylic felt). Each combination has been produced with four stitch variations. There are different types of stitches that can be done in a comforter to secure the felt in the middle layer, it also influences the thermal insulation. Four types of stitch variations have been chosen to compare the influence on thermal insulation property of a comforter. They are vertical, karo step, sewn thru and framed sewn thru. So finally, sixteen combinations have been chosen and analyzed for quality performance tests. The performances are compared and evaluated. The end product has been developed as a comforter with $\mathrm{CF} 2 \mathrm{C}$ combination and a sewn through stitch variation which gives better thermal insulation.

Keywords: polyester, comforter, feathers.

Citation: Srikrishnan M.R., Archana N., Niresh J. The evolution of a tri-layer comforter by using an acrylic felt nonwoven fabric, J. Sib. Fed. Univ. Eng. \& Technol., 2020, 13(5), 536-553. DOI: 10.17516/1999-494X-0245

(C) Siberian Federal University. All rights reserved

This work is licensed under a Creative Commons Attribution-Non Commercial 4.0 International License (CC BY-NC 4.0).

* Corresponding author E-mail address: krkrishnapsg32@gmail.com 


\title{
Разработка технологии получения трехслойного пледа с использованием акрилового \\ войлочного нетканого материала
}

\author{
М.Р. Шрикришнан, Н. Арчана, Дж. Ниреш \\ Политехнический институт \\ Индия, Коимбатур
}

\begin{abstract}
Аннотация. Целью данного исследования является разработка домашнего текстильного изделия, а именно пледа, с использованием войлока. Коммерческие трехслойные пледы состоят из двух наружных слоев ткани со слоем утеплителя между ними, т.е. средний слой выполнен из ватина, обычно изготовленного из пуховых перьев, полиэстера или шерсти.

Четыре общие основные комбинации, рассмотренные в данном исследовании, включают в себя XВ1X, ХВ2Х, БВ1Б, БВ2Б (X - хлопок, Б - бамбук, В1 - акриловый войлок 270 г/м2, В2 акриловый войлок 370 г/м2). Каждая комбинация была выполнена четырьмя типами стежков. Существуют различные типы стежков, выполняемых в пледе, чтобы закрепить войлок в среднем слое, что также влияет на теплоизоляцию. Чтобы сравнить влияние стежков на теплоизоляционные свойства пледа, были выбраны четыре их типа: вертикальный, шаг каро, втачной и окантовочный. Итак, были выбраны и проанализированы шестнадцать комбинаций для проведения испытаний на качество. Все характеристики сравнили и провели оценку. В качестве конечного продукта был разработан плед с комбинацией XВ2X и втачным типом стежка, который дает лучшую теплоизоляцию.
\end{abstract}

Ключевые слова: полиэстер, плед, перья.

Цитирование: Шрикришнан, М.Р. Разработка технологии получения трехслойного пледа с использованием акрилового войлочного нетканого материала / М.Р. Шрикришнан, Н. Арчана, Дж. Ниреш // Журн. Сиб. федер. ун-та. Техника и технологии, 2020. 13(5). C. 536-553. DOI: 10.17516/1999-494X-0245

\section{Introduction}

\subsection{Comforter}

A comforter is a type of bedding consisting of natural or synthetic insulative material encased in a fabric shell/covering, used to keep bed occupants warm. Like quilts, comforters are generally laid over a top bed sheet (and sometimes also blankets). Duvets are another form of quilt, traditionally filled with feathers though often made of synthetic fibers.

A comforter is sometimes covered for protection and prolonged use. Comforter covers are similar in principle to pillowcases, usually closed with zippers or buttons.

The terminology comforter comes from the word comfort. Comforters are usually used in the winter season when it is very cold. Due to the large thickness of a comforter, a person would feel warm and comfortable.

Comforter sizes correspond with bed sizes: twin, full, queen, king, and calking. Comforter sizes run slightly larger than actual bed sizes to allow for draping over the sides of the bed. Typical sizes in the United States for comforters are:

- Twin = 64" $(162.56 \mathrm{~cm})$ width x 87" $(220.98 \mathrm{~cm})$ length

- Queen / Full = 87" (220.98 cm) width x 87" $(220.98 \mathrm{~cm})$ length

- King = 101" $(256.54 \mathrm{~cm})$ width $\times 90 "(228.6 \mathrm{~cm})$ length 
Comforters are filled with layers of material such as polyester batting, down feathers, wool, or silk. Comforters can also be made out of fur, usually with a backing of satin or silk. The loft of the filling determines the weight as well as the level of insulation. The comforter is stitched or quilted to secure the filling and keep it evenly distributed. The outer shells of comforters are typically constructed using cotton, silk, or polyester fabrics or blends, of varying thread counts. Comforter shells vary in design and color, often designed to coordinate with other bedding.

Today nonwoven plays an important role in textile markets. Especially the needle punched felt/ nonwoven has more demand in technical textile market, because of high durability than batting/other fillings. So, for our comforter product we have chosen felt as a middle layer. Since the main use of the comforter is intended to keep the user warm, it should give more thermal insulation. Presently acrylic fibers are gaining importance in home textiles due to their excellent physical and chemical properties. Acrylic naturally has more thermal insulation compared to other fibers. By considering this important aspect acrylic fibers have been made as felt by using needle punching process. The felt is also made in two different fabric weights. The outer shells of comforter have been constructed using cotton and bamboo fabric for providing comfort properties.

\subsection{Materials and Methods}

\section{Methodology}

\subsubsection{Outer layer}

The outer shells of comforter have been constructed using cotton and bamboo fabric for providing comfort properties.

Table 1. Raw material specifications

\begin{tabular}{|l|c|c|c|c|}
\hline \multicolumn{1}{|c|}{ Specification } & EPI & PPI & Count & GSM \\
\hline Cotton(C) & 56 & 52 & $20 \mathrm{~s}$ & 117 \\
\hline Bamboo(B) & 58 & 53 & $20 \mathrm{~s}$ & 120 \\
\hline
\end{tabular}

\subsubsection{Middle layer}

We have chosen felt as a middle layer. Since the main use of the comforter is intended to keep the user warm, it should give more thermal insulation. Presently acrylic fibers are gaining importance in home textiles due to their excellent physical and chemical properties. Acrylic naturally has more thermal insulation compared to other fibers. By considering this important aspect acrylic fibres has been made as felt using needle punching process. The felt is also made in two different GSM.

Table 2. Batting specification

\begin{tabular}{|c|}
\hline Specification \\
\hline Acrylic fiber, $64 \mathrm{~mm}$ long, 3 denier \\
\hline
\end{tabular}


F1-270 GSM Acrylic felt

F2-370 GSM Acrylic felt

\subsection{Stitch variation}

Four common major combinations taken for this study include CF1C, CF2C, BF1B, BF2B. Each combination has been produced with four stitch variations. So, finally, sixteen combinations have been chosen and analyzed for quality performance tests.

Vertical

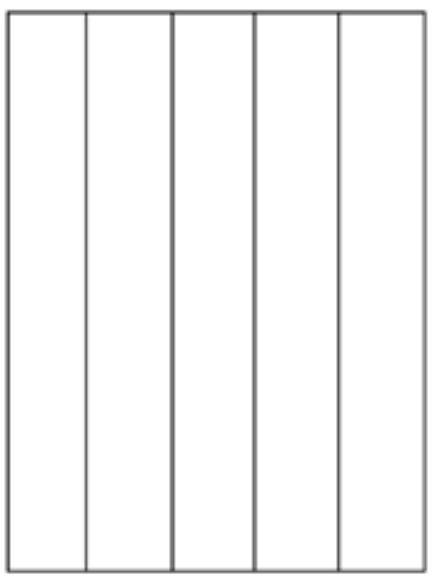

S1

Sewn thru

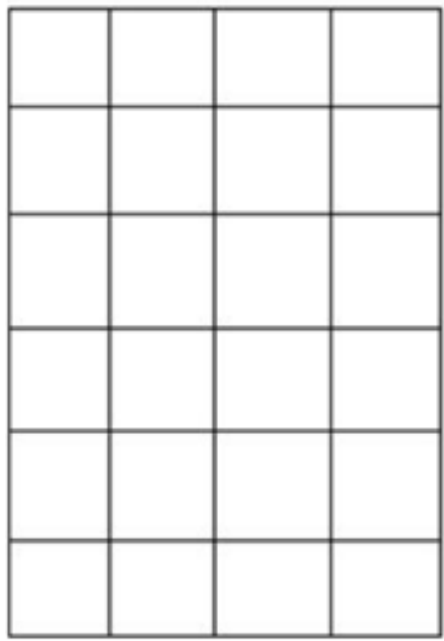

S3
Karo step

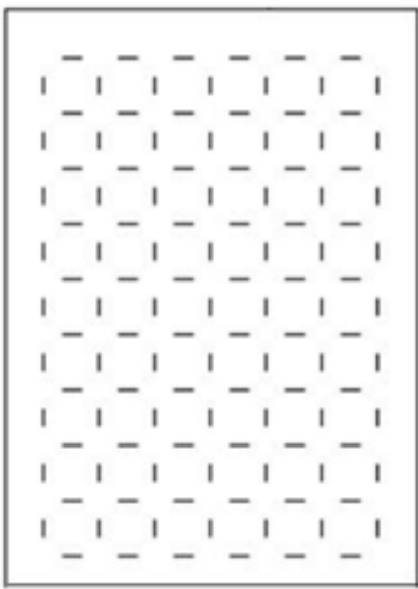

S2

Framed sewn thru

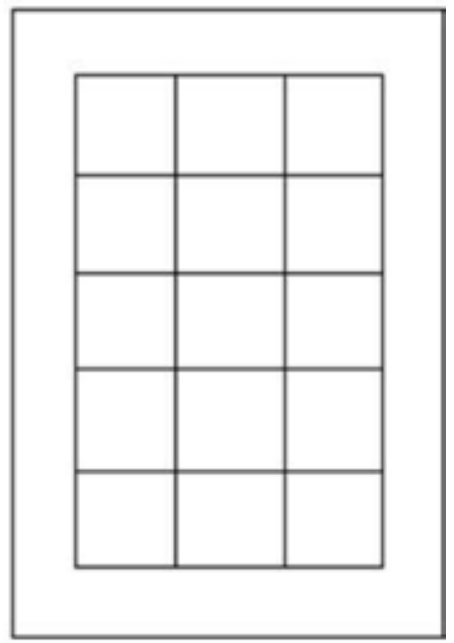

S4

Fig. 1. Stitch variations 


\subsection{Methodology}

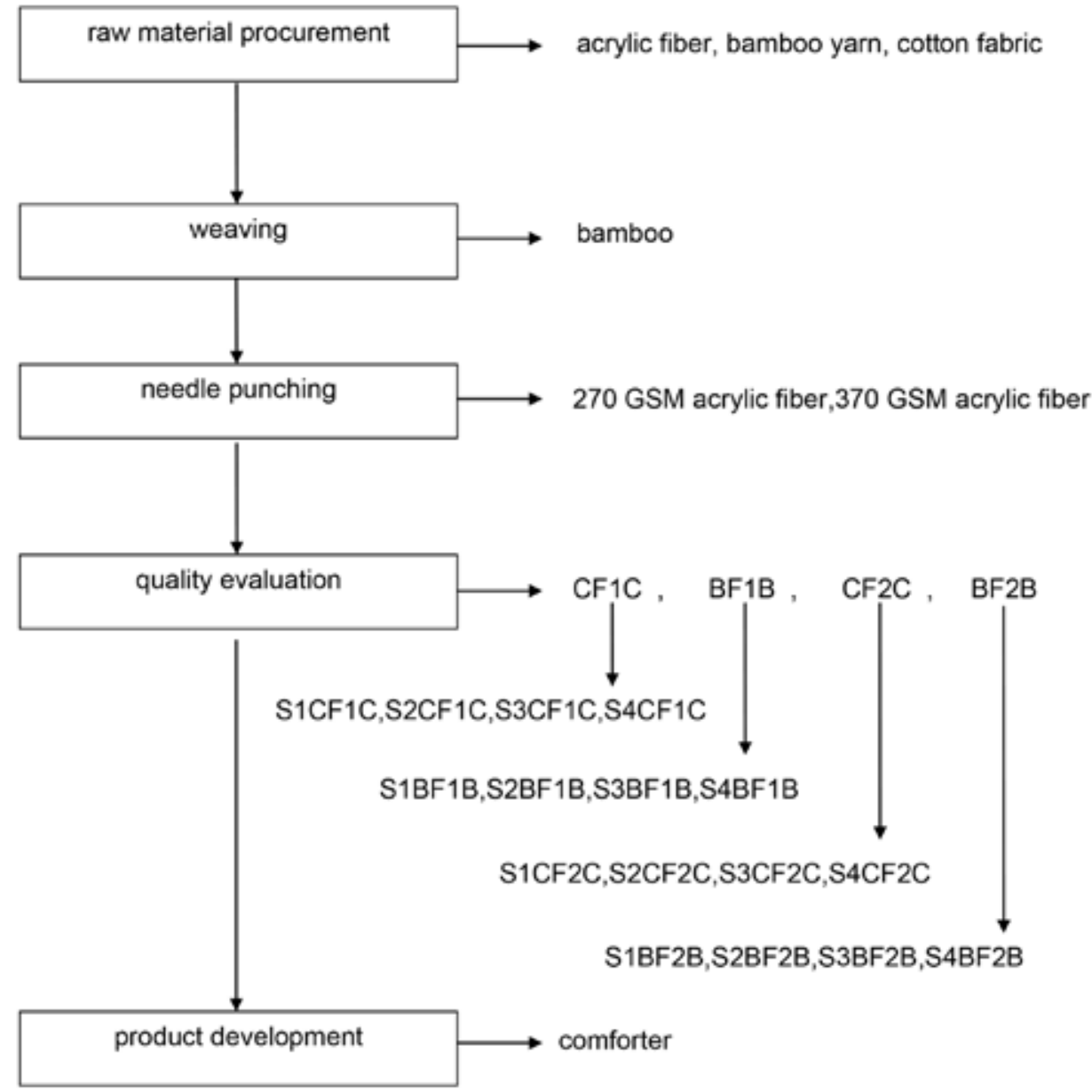

\begin{tabular}{|l|l|}
\hline \multicolumn{1}{|c|}{$\begin{array}{c}\text { Type of } \\
\text { Combination }\end{array}$} & \multicolumn{1}{c|}{ Material used } \\
\hline CF1C - & Cotton 270GSM acrylic felt cotton \\
\hline CF2C - & Cotton 370GSM acrylic felt cotton \\
\hline BF1B - & Bamboo 270GSM acrylic felt bamboo \\
\hline BF2B & Bamboo 370GSM acrylic felt bamboo \\
\hline S1CF1C & Vertical cotton 270GSM acrylic felt cotton \\
\hline S2CF1C & Karo step cotton 270GSM acrylic felt cotton \\
\hline S3CF1C & Sewn through box cotton 270GSM acrylic felt cotton \\
\hline S4CF1C & Framed sewn through cotton 270GSM acrylic felt cotton \\
\hline S1CF2C & Vertical cotton 370GSM acrylic felt cotton \\
\hline S2CF2C & Karo step cotton 370GSM acrylic felt cotton \\
\hline S3CF2C - & Sewn through box cotton 370GSM acrylic felt cotton \\
\hline S4CF2C - & Framed sewn through cotton 370GSM acrylic felt cotton \\
\hline S1BF1B - & Vertical bamboo 270GSM acrylic felt bamboo \\
\hline S2BF1B - & Karo step bamboo 270GSM acrylic felt bamboo \\
\hline S3BF1B & Sewn through box bamboo 270GSM acrylic felt bamboo \\
\hline
\end{tabular}


Journal of Siberian Federal University. Engineering \& Technologies 2020 13(5): 536-553

\begin{tabular}{|l|l|}
\hline $\begin{array}{c}\text { Type of } \\
\text { Combination }\end{array}$ & \multicolumn{1}{c|}{ Material used } \\
\hline S4BF1B - & Framed sewn through bamboo 270GSM acrylic felt bamboo \\
\hline S1BF2B - & Vertical bamboo 370GSM acrylic felt bamboo \\
\hline S2BF2B - & Karo step bamboo 370GSM acrylic felt bamboo \\
\hline S3BF2B - & Sewn through box bamboo 370GSM acrylic felt bamboo \\
\hline S4BF2B & Framed sewn through bamboo 370GSM acrylic felt bamboo \\
\hline
\end{tabular}

\section{SOURCING}

The acrylic fiber is sourced from Delhi.

The bamboo yarn is sourced from Pallava textile, Erode.

The cotton fabric is sourced from Erode.

\subsection{Weaving}

\subsubsection{Felt manufacturing}

A needle punched nonwoven is a fabric made from webs or batts of fibers where some of the fibers have been driven upward or downward by barbed needles. This needling action interlocks fibers and holds the structure together by friction forces.

Binding point is a set of fibers with various orientations, which are bonded by friction forces. In needle punching the bonding of the fiber web is the result of intertwining of the fibers and of the inter fiber friction caused by the compression of the web.

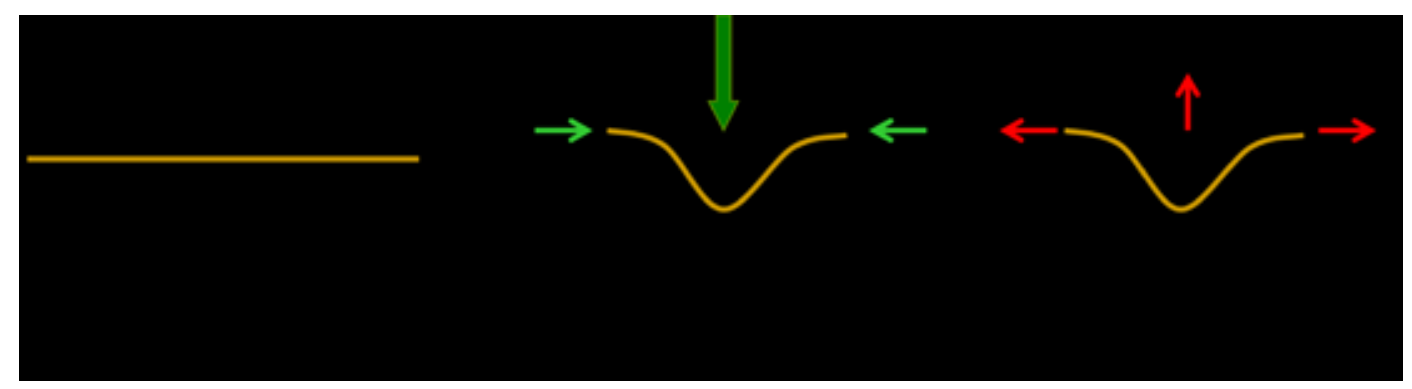

Fig. 2. Principle of Needle punching

The web is passed over a feed table, throw the drawing in rollers and via feed rollers, the web is fed to needling area. Here, the web is repeatedly punctured or perforated by a battery of needles and reoriented. This operation is carried out several times a minute. In modern machines it is carried out around 2000 strokes per minute. When the needling is done from above, as shown, the web is pressed against the lower boss, also known as the needle to throat plate; flat bed. The upper plate is called stripping plate or holding down plate.

As the needle return, the fibers remain in their new position virtually unchanged since the barbs only face in one direction. The deliver rollers transport the needle web from the needle zone. The material feed can be either intermittent or continues.

$$
-541-
$$


1. Fiber layer

2. Input device

3. Upper holeplate

4. Lower holenlate

5. Needle board

6. Needles

7. Main drive

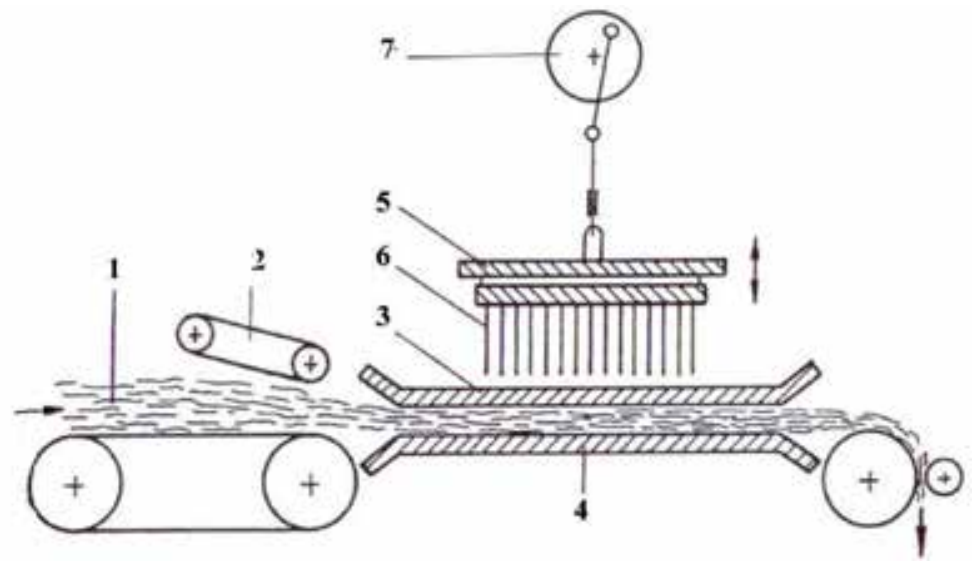

Fig. 3. Phases of Needle Punching Mechanism - caption

Table 3. Stich variations Illustrations

\begin{tabular}{|l|c|c|c|c|}
\hline \multicolumn{1}{|c|}{ STICH TYPE } & $\begin{array}{c}\text { Cotton 270 GSM } \\
\text { Felt cotton }\end{array}$ & $\begin{array}{c}\text { Cotton 370 GSM } \\
\text { Felt Cotton }\end{array}$ & $\begin{array}{c}\text { Bamboo 270 GSM } \\
\text { Felt Bamboo }\end{array}$ & $\begin{array}{c}\text { Bamboo 370 GSM } \\
\text { Felt Bamboo }\end{array}$ \\
\hline Vertical & S1CF1C & S1CF2C & S1BF1B & S1BF2B \\
\hline Karo Step & S2CF1C & S2CF2C & S2BF1B & S2BF2B \\
\hline Sewn Through & S3CF1C & S3CF2C & S3BF1B & S3BF2B \\
\hline $\begin{array}{l}\text { Framed Sewn } \\
\text { Through }\end{array}$ & S4CF1C & S4CF2C & S4BF1B & S4BF2B \\
\hline
\end{tabular}

To achieve the desired compression and bonding, it is common practice to have several needling zones in a row, one after another, with different needle settings and direction of stitching.

\section{Testing}

\subsection{Seam strength test (ASTM D1683)}

The British standard test for seam slippage is a test of the second type. Five warp and five weft specimens each $100 \mathrm{~mm}$ X $350 \mathrm{~mm}$ are used. Each sample is folded $100 \mathrm{~mm}$ from one end and a seam is sewed $20 \mathrm{~mm}$ from the fold line using the special sewing thread and sewing machine settings which are detailed in the standard. The layout of the sample is shown after sewing the folded part of the fabric is cut away $12 \mathrm{~mm}$ from the fold line leaving the seam $8 \mathrm{~mm}$ from the cut edge. A standard strength tester equipped with $25 \mathrm{~mm}$ grab test jaws is used, the gauge length is set to $75 \mathrm{~mm}$.

Just before the test the sample is cut into two parts one with the seam and one without it but with each part containing the same set of warp or weft threads. The sample without a seam is first stretched in the tensile tester up to a load of $20 \mathrm{ON}$ and a force elongation curve drawn. The matching sample with the seam is then tested in the same way making sure that the force elongation curve starts from the same zero position. The horizontal separation between the curves is then due to opening of the seam.

In order to find the force required to open the seam at a given distance, the separation of the curves at a force of $5 \mathrm{~N}$ is measured and this distance is added to the seam opening specified (usually $6 \mathrm{~mm}$ but 


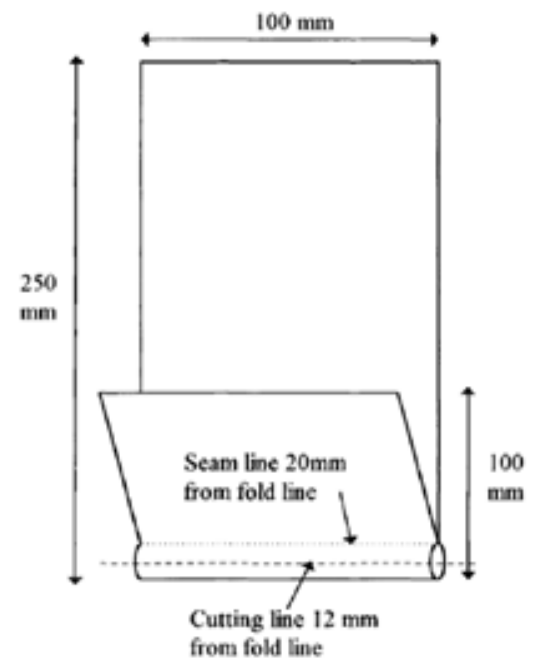

Fig. 4. Seam strength specimen

some specifications require $5 \mathrm{~mm}$ ) making appropriate allowance for the horizontal scale of the chart. Next the point on the curves where there is a separation of this distance is located and the value of load at this point is read off the chart. If the curves do not reach the specified separation below $20 \mathrm{ON}$, then the result is recorded as 'more than 20ON'.

\subsection{Comforter loft property}

Comforters are filled with layers of material such as polyester batting, down feathers, wool, or silk. Comforters also can be made out of fur, usually with a backing of satin or silk. The loft of the filling determines the weight as well as the level of insulation. The comforter is stitched or quilted to secure the filling and keep it evenly distributed. This test method is designed to measure the loft of a comforter in pre-wash and post wash conditions.

A comforter is taken from its packaging, shaken, laid flat on a hard surface and allowed to condition for a minimum of 15 minutes. A rigid, lightweight item such as a wooden yardstick or a piece of foam-core board is set on top of the comforter and at least $28 \mathrm{in}$. is on top of the comforter and at least $1.5 \mathrm{in}$. overlaps the edge of the comforter. Using a metal ruler, technician measures the distance from the table top to the bottom of the rigid item at the edge of the comforter. This measurement is performed along the comforter's edge at the mid-point between two corners. The point of measurement is clearly marked. This procedure is then repeated along the remaining three sides of the comforter. The four measurements are averaged and reported as pre-wash loft. The comforter is laundered according to the labelled care instructions and measuring process is repeated at the same points previously marked. The averaged measurement, taken after washing is reported as after wash loft.

Metal ruler with markings of 1/32 inch and a flat lightweight rigid object are used. Suitable items include rigid wooden yardsticks or pieces of foam core board measuring at least 30 inch in length.

Pre-wash measurement removes comforter from packaging. Shake comforter and lay flat in single layer tabletop. The edge of the comforter being measured must be no closer than 3 inches from the 
edge of the table. Remaining edges may hang over tabletop if size requires. Leave the comforter in this condition for a minimum of 15 minutes.

Post-wash measurement removes comforter from dryer. If comforter is to be stored for a period of time after washing and before measuring, loosely fold and do not compress. Repeat steps as above.

Loft measurement is determined by placing the rigid lightweight object onto the comforter surface, so that approximately 28 inches are on the comforter and the remainder protrudes over the edge. Measure to the nearest of $1 / 32$ inch the distance from the bottom of the light weight rigid object to the top of the table. Mark the spot on the comforter from which the measurement was taken. Record this measurement. The comforter is measured at the mid-point between two corners, using the method described above. The measuring process is repeated on remaining sides resulting in a total of four measurements. These four measurements are recorded and averaged. The average is reported as comforter loft. Wash measurement steps are repeated after the comforter has been laundered. Measurements are taken at the same mid-points marked as above. This average is reported as after wash comforter loft.

\subsection{Comforter}

\section{Product development}

Cut the cotton fabric of length 60 " and width 50 " which has been used as outer layer. Cut the felt three times with length 60 " and width 17 "which has been used as middle layer. Place the cotton fabric and felt like a sandwich. Now start giving sewn thru stitch through the length of the fabric. The edges have been finished with piping.

This chapter depicts the results of mechanical and physical properties of developed samples like air permeability, water vapor permeability, abrasion resistance, comforter loft property test, thermal conductivity, seam strength test and tensile strength test. They are done according to the requirements of the comforter which is developed.

\section{Results and discussion}

\subsection{Comforter}

\subsubsection{Air permeability test-ASTM D737-04(2008) E2 Standard}

The resistance values (R) as noted from KES air permeability tester are as follows in table below. The test results are shown in a bar graph below.

Table 4. Air permeability test

\begin{tabular}{|c|c|c|}
\hline S.No & Variation & Air permeability $\left(\mathrm{c}^{3} \mathrm{~cm}^{2} \mathrm{~s}\right)$ \\
\hline 1 & CF1C & 10.92 \\
\hline 2 & CF2C & 10.73 \\
\hline 3 & BF1B & 37.74 \\
\hline 4 & BF2B & 33.66 \\
\hline 5 & Commercial & 40.43 \\
\hline
\end{tabular}




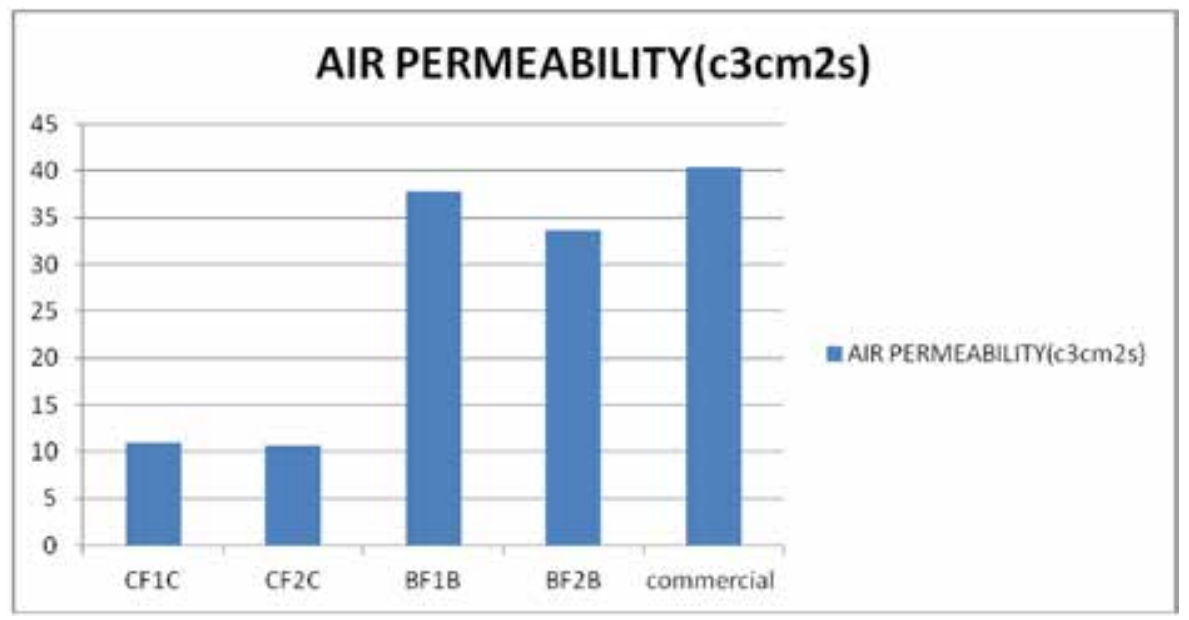

Fig. 5. Air permeability test

\section{Inference}

Since cross section of the bamboo fibre has micro pores, it allows more air to pass through it easily. So, air-permeability of bamboo felt combination is higher than cotton felt combination. So, as far as comforter is concerned air permeability is not at all required, only air entrapment is required in order to retain heat inside the fabric. So, this bamboo felt combination is not appropriate for development of comforter. If the fabric is permeable to air, then heat will not get retained by the fabric layer, so, the required level of warmness which the comforter is expected to provide will not be achieved.

\subsubsection{Water vapor permeability Test - BS 7209 Standard}

The BS standard was used to assess the water vapor permeability of commercially available and developed sample and results are tabulated below.

Table 5. Water vapor permeability

\begin{tabular}{|c|c|c|}
\hline S.No & Variation & Water vapor permeability $\left(\mathrm{g} / \mathrm{m}^{2} / \mathrm{day}\right)$ \\
\hline 1 & CF1C & 1469.5 \\
\hline 2 & CF2C & 1141.4 \\
\hline 3 & BF1B & 2349 \\
\hline 4 & BF2B & 1890.4 \\
\hline
\end{tabular}




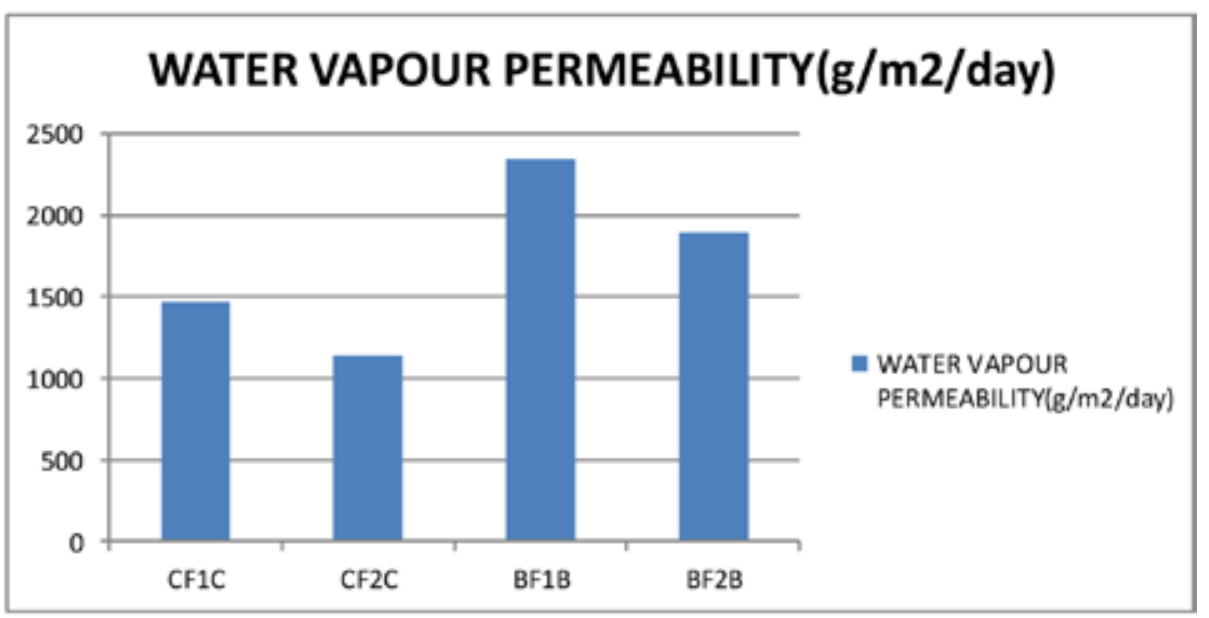

Fig. 6. Water vapor permeability test

\section{Inference}

Since cross section of the bamboo fibre felt combination has micro pores, it allows more water vapor to pass through it easily. So, water vapor permeability of bamboo felt combination is higher than cotton felt combination. So, as far as comforter is concerned water vapor permeability is not at all required, only air entrapment is required in order to retain heat inside the fabric. So, this bamboo felt combination is not appropriate for development of comforter. If the fabric is permeable to water, then heat will not get retained by the fabric layer, so, the required level of warmness which the comforter is expected to provide will not be achieved.

\subsubsection{Abrasion resistance test -BS 5690 Standard}

The BS standard was used to assess the abrasion resistance of commercially available and developed sample and the results are tabulated below.

Table 6. Abrasion resistance

\begin{tabular}{|c|c|c|}
\hline S.No & Variation & Weight loss \% \\
\hline 1 & CF1C & 0.18 \\
\hline 2 & CF2C & 0.159 \\
\hline 3 & BF1B & 2.7 \\
\hline 4 & BF2B & 1.015 \\
\hline 5 & Commercial & 0.263 \\
\hline
\end{tabular}




\section{weight loss\%}

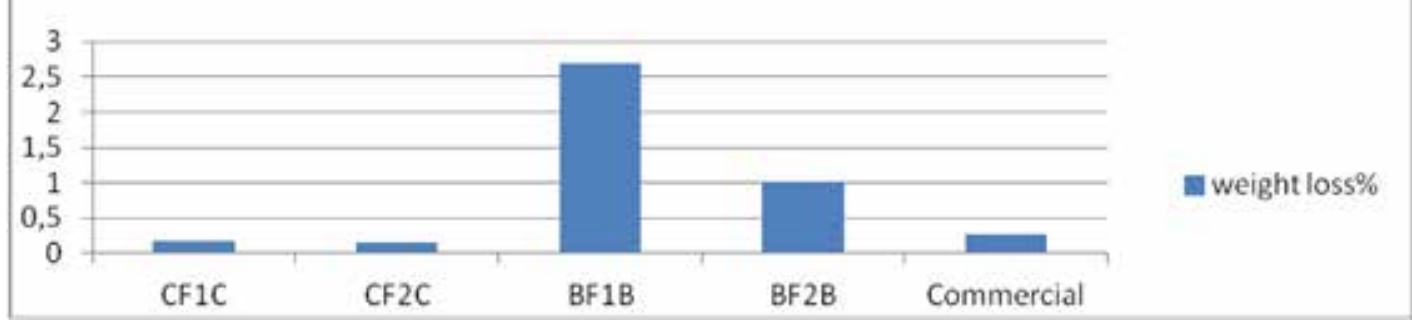

Fig. 7. Abrasion resistance

\section{Inference}

The Weight loss \% is higher for bamboo fabric and felt combination when compared against cotton fabric felt combination and also with commercial product. So, this in-turn reveals that the cotton fabric and felt combination has more abrasion resistance than bamboo fabric and felt combination. This is because as we are the consumers of this comforter. During sleeping the outer fabric layer in the comforter will get abraded with our human body according to different postures of our sleep. So, this will result in weight loss and the required amount of comfort and resiliency will be lost. So, as far as the testing result is concerned the cotton fabric and felt 2 combination the weight loss is less, so, this combination is highly required for our comforter.

\subsubsection{Thermal conductivity (Lee's disc method)}

\section{Cotton 270GSM acrylic felt cotton}

Table 7. Thermal conductivity of stitch variations in CF1C

\begin{tabular}{|c|c|c|}
\hline S.No & Variation & Thermal conductivity $\left(\mathrm{WK}^{-1} \mathrm{~m}^{-1}\right)$ \\
\hline 1 & S1CF1C & 0.0465 \\
\hline 2 & S2CF1C & 0.0574 \\
\hline 3 & S3CF1C & 0.03978 \\
\hline 4 & S4CF1C & 0.0504 \\
\hline
\end{tabular}

\section{Cotton 370GSM acrylic felt cotton}

Table 8. Thermal conductivity of stitch variations in CF2C

\begin{tabular}{|c|c|c|}
\hline S.No & Variation & Thermal conductivity $\left(\mathrm{WK}^{-1} \mathrm{~m}^{-1}\right)$ \\
\hline 1 & S1CF2C & 0.03338 \\
\hline 2 & S2CF2C & 0.044 \\
\hline 3 & S3CF2C & 0.0201 \\
\hline 4 & S4CF2C & 0.02993 \\
\hline
\end{tabular}




\section{Bamboo 270GSM acrylic felt bamboo}

Table 9. Thermal conductivity of stitch variations in BF1B

\begin{tabular}{|c|c|c|}
\hline S.No & Variation & Thermal conductivity $\left(\mathrm{WK}^{-1} \mathrm{~m}^{-1}\right)$ \\
\hline 1 & S1BF1B & 0.0493 \\
\hline 2 & S2BF1B & 0.0607 \\
\hline 3 & S3BF1B & 0.05077 \\
\hline 4 & S4BF1B & 0.06307 \\
\hline
\end{tabular}

\section{Bamboo 370GSM acrylic felt bamboo}

Table 10. Thermal conductivity of stitch variations in BF2B

\begin{tabular}{|c|c|c|}
\hline S.No & Variation & Thermal conductivity $\left(\mathrm{WK}^{-1} \mathrm{~m}^{-1}\right)$ \\
\hline 1 & S1BF2B & 0.03769 \\
\hline 2 & S2BF2B & 0.0537 \\
\hline 3 & S3BF2B & 0.04639 \\
\hline 4 & S4BF2B & 0.0441 \\
\hline
\end{tabular}

The thermal conductivity value for the commercial product is $0.3321 \mathrm{WK}^{-1} \mathrm{~m}^{-1}$.

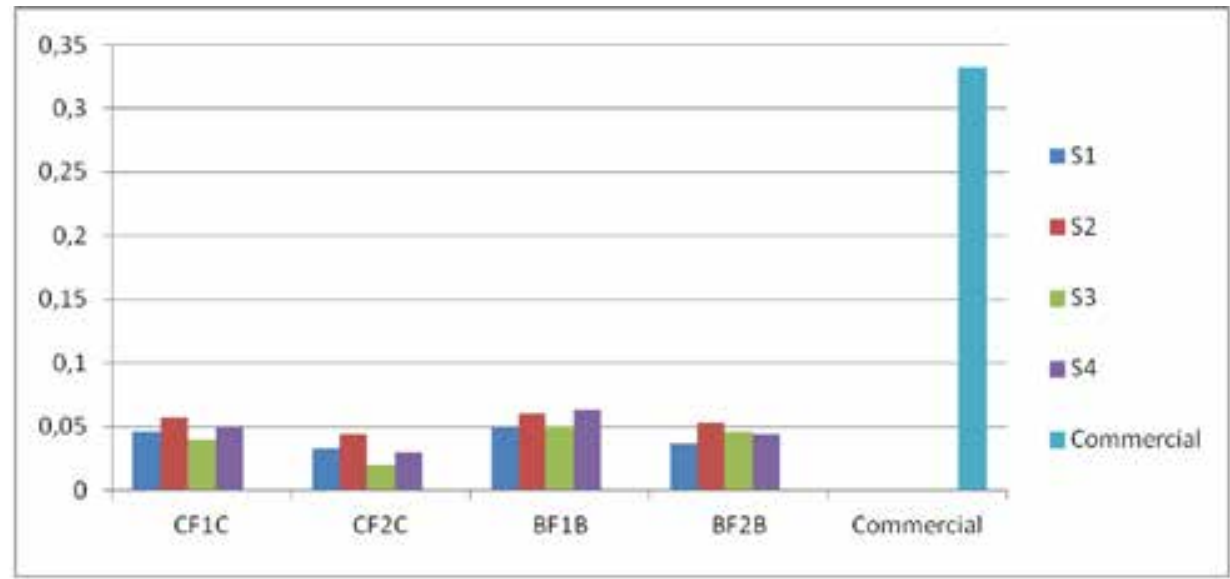

Fig. 8. Thermal conductivity

\section{Inference}

From the graph and test results we confirm that the thermal conductivity values are very low for $\mathrm{S} 3 \mathrm{CF} 2 \mathrm{C}$ combination when compared with other fabric combinations of all stich variations and also the thermal conductivity of commercial comforter is very high. So, this reveals that the thermal insulation value will be very high for S3CF2C combination which is highly required for comforter. 


\subsubsection{Thermal insulation}

\section{Cotton 270GSM acrylic felt cotton}

Table 11. Thermal insulation of stitch variations in CF1C

\begin{tabular}{|c|c|c|}
\hline S.No & Variation & Thermal insulation \\
\hline 1 & S1CF1C & 0.111 \\
\hline 2 & S2CF1C & 0.0821 \\
\hline 3 & S3CF1C & 0.124 \\
\hline 4 & S4CF1C & 0.1084 \\
\hline
\end{tabular}

\section{Cotton 370GSM acrylic felt cotton}

Table 12. Thermal insulation of stitch variations in CF2C

\begin{tabular}{|c|c|c|}
\hline S.No & Variation & Thermal insulation \\
\hline 1 & S1CF2C & 0.21 \\
\hline 2 & S2CF2C & 0.165 \\
\hline 3 & S3CF2C & 0.3177 \\
\hline 4 & S4CF2C & 0.1795 \\
\hline
\end{tabular}

\section{Bamboo 270GSM acrylic felt bamboo}

Table 13. Thermal insulation of stitch variations in BF1B

\begin{tabular}{|c|c|c|}
\hline S.No & Variation & Thermal insulation \\
\hline 1 & S1BF1B & 0.107 \\
\hline 2 & S2BF1B & 0.069 \\
\hline 3 & S3BF1B & 0.0884 \\
\hline 4 & S4BF1B & 0.0749 \\
\hline
\end{tabular}

\section{Bamboo 370GSM acrylic felt bamboo}

Table 14. Thermal insulation of stitch variations in BF2B

\begin{tabular}{|c|c|c|}
\hline S.No & Variation & Thermal insulation \\
\hline 1 & S1BF2B & 0.167 \\
\hline 2 & S2BF2B & 0.117 \\
\hline 3 & S3BF2B & 0.128 \\
\hline 4 & S4BF2B & 0.156 \\
\hline
\end{tabular}

The thermal insulation value for the commercial product is 0.01033 .

$$
-549-
$$




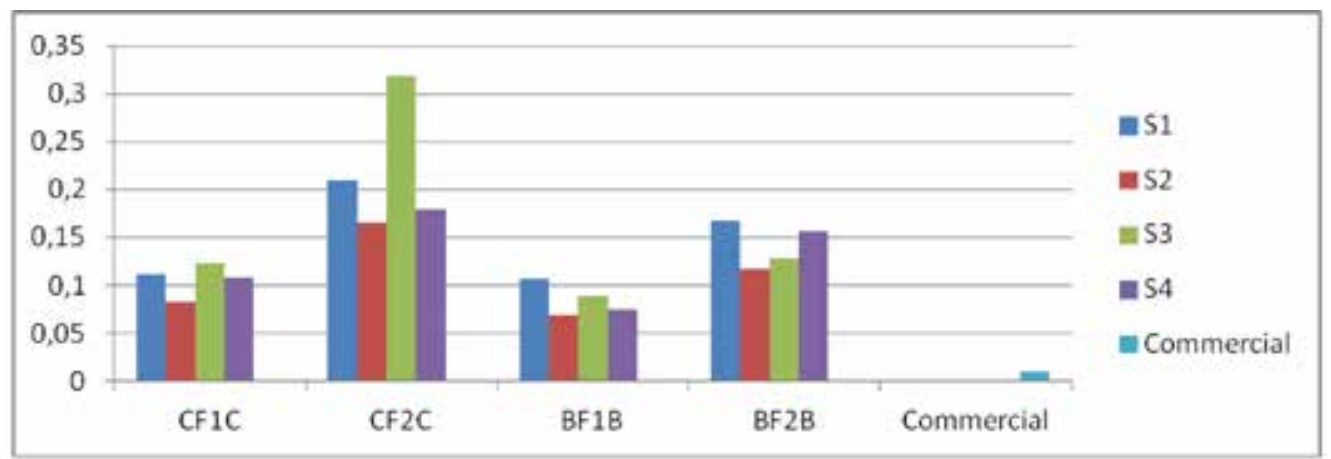

Fig. 9. Thermal insulation

\section{Inference}

Since air entrapment is more for sewn thru combination of 370 GSM felt with cotton as outer layer, the thermal insulation will be better for S3CF2C. The fibres in felt are more intact than in normal filling which causes poor thermal insulation in commercial product. So, with the use of felt the thermal property of comforter can be improved.

\subsubsection{Seam strength test (ASTM D1683)}

Table 15. Seam strength test

\begin{tabular}{|c|c|c|}
\hline S.No & Variation & Seam strength(lbs) \\
\hline 1 & CF1C & 100 \\
\hline 2 & CF2C & 140 \\
\hline 3 & BF1B & 90 \\
\hline 4 & BF2B & 165 \\
\hline
\end{tabular}

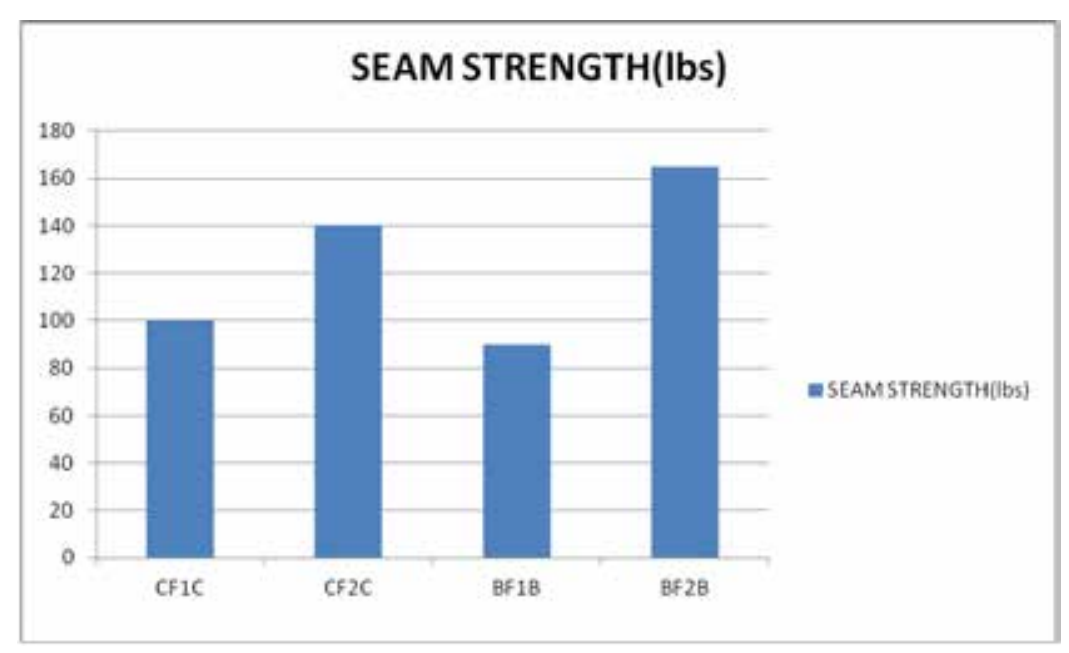

Fig. 10. Seam strength test 


\section{Inference}

From the graph, seam strength of the bamboo fabric and felt 2 combination is higher when compared with other three-layer combinations. And, also, more the weight of felt higher is the seam strength. Also, as far the graph results are concerned the cotton felt 2 cotton combination is also having more seam strength and occupies the second position.

Table 16. Tensile strength test (ASTM D5034)

\begin{tabular}{|c|c|c|}
\hline S.No & Description & Tensile strength(lbs) \\
\hline 1 & Cotton & 125 \\
\hline 2 & Bamboo & 120 \\
\hline 3 & 270 Grams/square metre felt & 205 \\
\hline 4 & 370 Grams/square metre felt & 240 \\
\hline
\end{tabular}

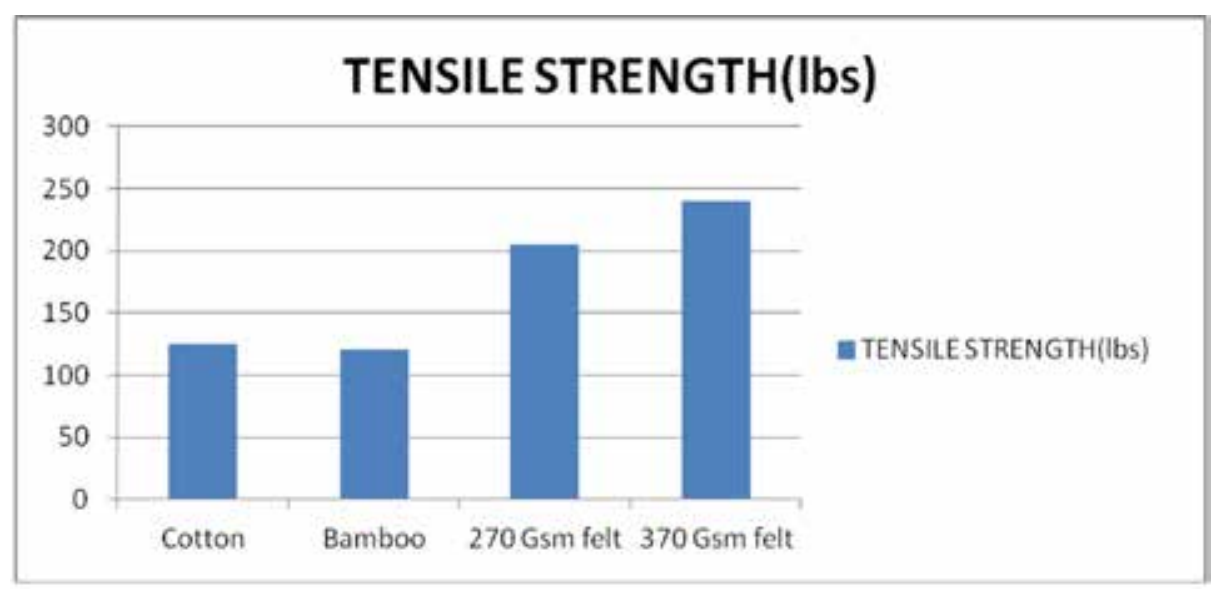

Fig. 11. Tensile strength test

\section{Inference}

From the graph, tensile strength of the cotton fabric layer and felt 2 combination is higher, when compared with other layer combinations. And, also, the more the weight of felt higher is the tensile strength.

\subsubsection{Comforter loft property test (CTL test method)}

The comforter loft variation for $370 \mathrm{gsm}$ felt is -0.0393 inches and for $270 \mathrm{gsm}$ felt is -0.01968 inches. The comforter loft variation for commercial product is +0.0787 inches.

\section{Inference}

Since the felt structure holds the fibres strongly than normal filling, the loft variation is better for comforters using felt. 


\section{Conclusion}

1. In this project, the various physical and mechanical properties such as air permeability, water vapor permeability, abrasion resistance, thermal insulation, seam strength, tensile strength and comforter loft property of both commercial and developed samples were analyzed. They are done according to the international standards and the results are compared.

2. The cross section of the bamboo fiber has micro pores, it allows more air to pass through it easily. So, air-permeability and water vapor permeability of bamboo is higher than cotton and the commercially used fabric. Since cross section of the bamboo fibre has micro pores, it allows more air to pass through it easily. So, air-permeability of bamboo felt combination is higher than cotton felt combination. So, as far as comforter is concerned air permeability is not at all required, only air entrapment is required in order to retain heat inside the fabric. So, this bamboo felt combination is not appropriate for development of comforter. If the fabric is permeable to air, then heat will not get retained by the fabric layer, so, the required level of warmness which the comforter is expected to provide will not be achieved.

3. The Weight loss \% is higher for bamboo fabric and felt combination when compared with cotton fabric felt combination and, also, with commercial product. So, this in-turn reveals that the cotton fabric and felt combination has more abrasion resistance than bamboo fabric and felt combination. This is because as we are the consumers of this comforter. During sleeping the outer fabric layer in the comforter will get abraded with our human body according to different postures of our sleep. So, this will result in weight loss and the required amount of comfort and resiliency will be lost. So, as far as the testing result is concerned the cotton fabric and felt 2 combination the weight loss is less, so this combination is highly required for our comforter.

4. From the graphs and test results we confirm that the thermal conductivity values are very low for S3CF2C combination when compared with other fabric combinations of all stich variations and, also, the thermal conductivity of commercial comforter is very high. So, this reveals that the thermal insulation value will be very high for $\mathrm{S} 3 \mathrm{CF} 2 \mathrm{C}$ combination which is highly required for comforter.

5. The thermal conductivity values are very low for S3CF2C combination when compared with other fabric combinations of all stich variations and also the thermal conductivity of commercial comforter is very high. So, this reveals that the thermal insulation value will be very high for S3CF2C combination which is highly required for comforter.

6. Since air entrapment is more for sewn thru combination of $370 \mathrm{GSM}$ felt with cotton as outer layer, the thermal insulation will be better for S3CF2C. The fibres in felt are more intact than in normal filling which causes poor thermal insulation in commercial product. So, with the use of felt the thermal property of comforter can be improved.

7. Seam strength of the bamboo fabric and felt 2 combination is higher. When compared with other three-layer combinations. And, also, the higher the weight of felt higher the seam strength. Also, as far as the graph results are concerned the cotton felt 2 cotton combination is also having more seam strength and occupies the second position.

8. Tensile strength of the cotton fabric layer and felt 2 combination is higher, when compared with other layer combinations. And, also, the more the weight of felt higher the tensile strength.

9. Since the felt structure holds the fibres strongly than normal filling, the loft variation is better for comforters using felt. 
10. The final product has been made with this combination.

11. When compared with commercial product, comforter developed by using felt shows better performance.

\section{References}

[1] Bobar D. Badische Anilin- \& Soda-Fabrik (BASF). Non woven Floor Coverings. West Germany

[2] Anjali Karolia and Surbhi Sardiwal. Developmental initiatives for the revival of 'Tonk Namada' - A Traditional Felted Floor Covering of Rajasthan. Textile review, 2011, 7 (7), 12-16.

[3] Saville B.P. Physical testing of textiles. Woodhead publishing, Cambridge England, 1999.

[4] Subrata Das. Performance of Home textiles. Woodhead publishing, India, 2010.

[5] Hwan Kuk Kim, Dae Kyu Park, Du Hwan Chun. A Study on the reliability evaluation of industrial felt. Fibers and Polymers, 2015, 16, 1441-1447.

[6] Vinay Kumar Midha and Mukhopadyay A. Bulk and physical properties of needle-punched Nonwoven fabrics. Indian Journal of Fibre and Textile Research, 2005, 30(2), 218-229.

[7] Gioello Debbie Ann. Profiling Fabrics: properties, performance \& construction techniques. New York: Fairchild Publications, 1981.

[8] McDowell Colin. Hats: Status, Style and Glamour. New York: Rizzoli. Paperback - May 1, 1997.

[9] Anne Barnett. Examining Textiles Technology. Heinemann, 1997.

[10] Oldyreva A., Ledeneva I. Influence of Waterproof Processing on Hygienic Properties of Felt Footwear. Tekstilna industrija, 2013, 61 (1), 16-17.

[11] WIRA. The production and finishing of needle felted non woven blazer cloths, 1976.

[12] Xavier Thibault, Jean-Francis Bloch. Structural analysis by X-ray microtomography of a strained Non woven Papermaker felt. Textile Research Journal, 2002, 72(6), 480-485.

[13] Industrie Tessili Bresciane Srl. [Electronic recourse] - Access: www.itb-felts.com

[14] Hawks Leona K. Selecting a carpet and pad. Home Improvement, 1987, 5. 